\title{
Current Methods of Human and Animal Brucellosis Diagnostics
}

\author{
Ekaterina A. Smirnova ${ }^{1}$, Andrey V. Vasin ${ }^{1}$, Nurlan T. Sandybaev ${ }^{2}$, Sergey A. Klotchenko ${ }^{1}$, \\ Marina A. Plotnikova ${ }^{1}$, Olga V. Chervyakova ${ }^{2}$, Abylai R. Sansyzbay ${ }^{2}$, Oleg I. Kiselev ${ }^{1}$ \\ ${ }^{1}$ Laboratory of Structural and Functional Proteomics, Research Institute of Influenza of the Ministry of Health of the Russian Federa- \\ tion, St. Petersburg, Russia; ${ }^{2}$ Research Institute for Biological Safety Problems of the RK NBC/SC ME\&S RK, Gvardeiskiy, Repub- \\ lic of Kazakhstan. \\ Email: vasin@influenza.spb.ru
}

Received April 22 $2^{\text {nd }}, 2013$; revised May $22^{\text {nd }}, 2013$; accepted June $22^{\text {nd }}, 2013$

Copyright (C) 2013 Ekaterina A. Smirnova et al. This is an open access article distributed under the Creative Commons Attribution License, which permits unrestricted use, distribution, and reproduction in any medium, provided the original work is properly cited.

\begin{abstract}
Brucellosis is an urgent infectious disease of livestock and wild animals and the commonest human zoonosis. Diagnosis of brucellosis is rather complicated and it has to be obligatorily confirmed by laboratory testing. Direct bacteriological and molecular methods and indirect serological tests are used for brucellosis diagnostics. The choice of the diagnostic tools depends on the overall epidemiological situation in the region and the objectives of the study: validation of the diagnosis, screening (monitoring), cross-sectional studies or confirmation of brucellosis-free status of the region. The review describes current bacteriological, serological and molecular methods, routinely used for the diagnosis of brucellosis in humans and animals. The perspectives of brucellosis diagnostics are also discussed.
\end{abstract}

Keywords: Brucellosis; Diagnostics; Bacteriology; Polymerase Chain Reaction; Serology

\section{Introduction}

Brucellosis is a widespread infectious disease of livestock and wild animals and the commonest human zoonosis. The etiological agents of brucellosis are Brucella species - small, Gram-negative, aerobic, facultative intracellular, coccobacilli bacteria. About 10 Brucella species are currently known. They infect sheep (Brucella ovis), goats (Brucella melitensis), cattle (Brucella abortus), pigs (Brucella suis), dogs (Brucella canis), rodents (Brucella neotomae, Brucella microti) and some marine mammals, mostly cetacean (Brucella ceti) and seals Brucella pinnipedialis) [1]. In animals, brucellosis predominantly affects the reproductive system inducing abortions and reduced fertility. Human brucellosis is characterized by a long-term progression and the disorders of the nervous and cardiovascular systems and osteoarticular apparatus. The disease often leads to a partial or complete loss of the physical efficiency [2]. Brucella melitensis, Brucella suis, Brucella abortus and Brucella canis are the most frequently occurred Brucella species transmitted from animals to humans [3].

In spite of a significant progress in the brucellosis control, there still remain regions where the infection persists in domestic animals and, therefore, transmission to the human population frequently occurs. According to the World Health Organization data, more than half of a million human brucellosis cases are officially registered each year [4]. The traditional regions of human brucellosis spread are the countries of Mediterranean basin, the Near East, South America, and possibly sub-Saharan Africa [5]. However, the global epidemiology of brucellosis has greatly evolved over the past 15 years and new foci of human brucellosis have arrived, particularly in the Central Asia. The Middle East has traditionally been considered as an endemic area. Indeed, five of the ten countries with the highest incidence for human brucellosis are in this area, including Syria that has the highest annual incidence of brucellosis worldwide [5]. Seven republics of the former Soviet Union (Kyrgyzstan, Tajikistan, Kazakhstan, Azerbaijan, Turkmenistan, Armenia and Uzbekistan) are included in the 25 countries with the highest incidence of the disease worldwide, while another country of this region, Mongolia, is ranked the second [5]. These countries have emerged as the most important loci of human brucellosis worldwide in recent years. Since brucellosis is a serious public-health problem, the disease control has become a national priority in 
these countries.

Besides a threat to human healthware brucellosis spread in livestock foci is also causing serious problems to the national economies. According to the International agreements on the veterinary regulation [6] if brucellosis is detected in at least one herd, the resettlement and sale of animals from the whole foci region should be prohibited. Such strict limitations lead to the significant brucellosis mediated economic losses. International studies confirm that the incidence of human brucellosis is significantly reduced in the regions where the brucellosis foci among domestic and wild animals are completely eliminated [5]. A crucial step for the detection and elimination of brucellosis is a timely and accurate diagnosis.

Brucellosis diagnosis is rather complicated because the disease may have an incubation period varying from 5 days to 5 months and can progress in various forms: acute, chronic or asymptomatic [7]. Symptoms of the acute phase of brucellosis-fever and weakness in humans and abortion in animals - are common to a wide range of different diseases [1]. Therefore the final diagnosis of brucellosis has to be obligatorily confirmed by laboratory testing.

Brucellosis diagnostics is based on bacteriological and molecular methods (direct tests), and serological in vitro and allergic in vivo methods (indirect tests) [2]. The choice of the diagnostic method depends on the overall epidemiological situation in the region and the objectives of the study: validation of the diagnosis, screening (monitoring), cross-sectional studies or confirmation of brucellosis-free status of the region [1].

\section{Bacteriological Methods}

The "gold standard" of the brucellosis diagnosis is the direct bacteriological testing: cultivation of Brucella, isolated from body fluids (blood, cerebrospinal fluid, urine and others) or tissues [8]. Identification of bacteria is based on their morphology, staining and metabolic profile (tests for catalase, oxidase and urease activities) [1]. For blood and other body fluids culturing the biphasic method of Castaneda is recommended [2]. Bacteriological diagnosis of brucellosis is severely limited by the fact that Brucella is a hazardous bacterium, and its isolation has to be done in specially equipped level 3 laboratories. Moreover, it is a very labor-intensive and timeconsuming procedure. However, the isolation and cultivation of bacteria are also necessary preliminary steps for staining and biotyping of Brucella species.

The staining of bacterial isolates using Stamp method is the classical direct method of brucellosis diagnosis. It consists of the basic fuchsine staining followed by de-colorization with diluted acetic acid. Despite the fact that this method is non-specific and some other patho- genic bacteria such as Chlamydophila abortus and Coxiella burnrtii will be colored in a similar way, it is often used to obtain the preliminary results [9].

Biotyping of Brucella species, isolated from the biological samples, provides significant epidemiological data that allow tracing the focus of infection and the ways of its spread. Classical biotyping of Brucella species is made on the base of phenotypic differences of surface lipopolysaccharide (LPS) antigens, sensitivity to staining, $\mathrm{CO}_{2}$ dependence, $\mathrm{H}_{2} \mathrm{~S}$ production and other metabolic properties, phage lysis, as well as the ability to grow in the presence of alkaline fuchsine or thionine [10]. Until recently, the methods of agglutination with antibodies against rough or smooth LPS, such as agglutination with antibodies against the $\mathrm{A}$ and $\mathrm{M}$ epitopes of O-polysaccharide chain, were widely used for biotyping. However, there is a cross-reaction with the epitopes of the surface LPSs from bacteria of some other genera, such as type of Yersinia. In addition, Brucella is a highly homomorphic genus and classic typing methods do not allow to differentiate isolates of the same species and biovars [11]. Moreover the classic methods of biotyping require standardized methods of analysis and highly qualified personnel to perform them and therefore are held almost exclusively in reference laboratories.

\section{Molecular Methods}

In order to avoid difficulties of bacteriological testing the molecular biological techniques, often based on the polymerase chain reaction (PCR) amplification, are successfully used for Brucella identification and typing [12]. The first crucial step of PCR based methods is DNA isolation from biological samples, since its quality has a significant impact on the sensitivity of the method $[13,14]$. Initially, PCR based identification has been developed for the determination of bacterial isolates [15], but now these methods are also used for detection of Brucella species in clinical samples of human and animals [13]. The most simple and reliable method of Brucella identification is PCR with a single pair of primers, specific to the bacterial DNA sequences, such as $16 \mathrm{~S}$ - 23S rRNA operon, IS711 or BCSP31 genes [1,13]. Using a combination of several primer pairs for amplification of BCSP31, OMP2B, OMP2A, OMP31 genes, encoding the external membrane proteins, it is possible to identify the four Brucella species: Brucella melitensis, Brucella suis, Brucella abortus and Brucella canis [16]. Another method, based on the combination of seven PCR reactions, allows discrimination between six Brucella species [17]. There are PCR methods for identification of some Brucella abortus biovars [18] and distinguishing between S19 and RB51 strains of Brucella abortus, used for vaccination against pathogenic strains $[19,20]$.

More effective method of diagnosis and identification 
of Brucella is multiplex PCR. It provides identification of all known Brucella species, including pathogens of marine mammals, at the species or even biovars level by using certain combinations of primer pairs. The first multiplex PCR based test for Brucella detection was developed in 1994 [21]. It allowed identification of the four Brucella species (Brucella abortus, Brucella melitensis, Brucella ovis and Brucella suis) and was named AMOS PCR for the first letters of species names. AMOS PCR identifies only a few biovars of each of the four species and can't distinguish individual biovars of the same species. Later on this method has been improved to detect more biovars and identify Brucella S19 and RB51 vaccine strains $[22,23]$.

Recently a number of real-time PCR methods for Brucella detection in clinical samples were developed. The advantages of real-time PCR are speed (since there is no need to analyze the PCR products by agarose gel electrophoresis) [24], high sensitivity in comparison to the conventional PCR [25], and reduced samples contamination. Various samples can be analyzed by this method, including cell culture, blood, serum, and tissues [26].

Other methods of PCR based identification of Brucella include a multilocus analysis of genome regions with a variable number of tandem repeats (MLVA) [27] and multi locus sequencing of genome regions of the bacterial isolate (MLSA) [28]. These methods are based on the quantifying the number of tandem repeats in a particular locus of bacterial genome and are used for Brucella genotyping not only at the level of genus and species, but also biovars.

Although up-to-date PCR-based methods of Brucella identification and genotyping have several advantages in comparison with classical bacteriological methods, they also have some significant problems. The sensitivity and accuracy of PCR based methods strongly depend on the methods of DNA isolation and the quality of the isolated DNA (especially for multiplex PCR). There still remains the problem of false negative results, because the PCR is inhibited in the presence of some admixtures, such as EDTA, RNAases, DNAases, gems, heparin, phenols, urea, and many others, from the clinical samples or DNA isolation and purification procedures. False positive results may also occur as a result of sample contamination. It is further necessary to develop the positive and negative controls and standardize the conditions for PCR reactions with clinical samples [24].

\section{Classical Serological Methods}

The indirect methods of brucellosis diagnostics are based on the detection of the immune response to a bacterial infection. Most of these methods have been initially developed for testing of cattle and then were used to test the domestic goats and sheep (except for the analysis of milk), and later were adapted for the monitoring of certain species of wild animals [1].

The most commonly used serological tests are based on the detection of antibodies against the smooth surface LPS, since they are immunodominant antigens of Brucella. For the specific detection of Brucella ovis and Brucella canis infection antibodies against rough LPSs of Brucella are used.

The indirect methods of brucellosis diagnostics include agglutination tests, complement fixation tests, precipitation tests and primary binding immunoassays $[2$, 29-34].

The first serological test for brucellosis-slow agglutination test (SAT) - was described in 1897, it is based on the sedimentation of the complexes of IgM antibodies with Brucella cell antigens [29]. The reaction is slow since it requires an overnight incubation at $37^{\circ} \mathrm{C}$. SAT lacks specificity and sensitivity, although it is inexpensive and easy to perform.

Another broadly used simple method of brucellosis diagnostics is the Rose Bengal test (RBT) [29]. It is a simple spot agglutination test where drops of stained antigen and serum are mixed on a plate and any resulting agglutination signifies a positive reaction. The results are received in several minutes. The test is an excellent screening test but may be oversensitive for diagnosis in individual animals, particularly vaccinated ones.

One of the approaches to remove none specific reactivity is the precipitation of high molecular weight serum glycoproteins. It is commonly done by addition of rivanol to serum followed by removal of the precipitate by centrifugation and either a rapid plate type agglutination test with undiluted serum or a tube test using serum dilutions starting at 1:25 [2].

Complement fixation tests provide the detection of anti-Brucella antibodies that are able to activate complement [31]. The complement system consists of a complex series of proteins which, if triggered by anantigen-antibody complex, react in a sequential manner to cause cell lysis. Since this test is difficult to standardize, it is progressively being replaced by primary enzyme-linked immunosorbent assays (ELISA) [2].

Indirect ELISA (iELISA) method is based on the specific binding of antibodies present in the test sample with immobilized antigen. The binding event is visualized using chemically or enzymatically derived fluorescent, luminescent or colorimetric reaction. Many iELISA tests are available on the market [2].

Antibodies against smooth LPS are used in all the above mentioned tests. They have a common significant disadvantage: O-polysaccharides of Brucella are similar to that of Yersinia enterocolitica and other bacteria. It leads to the false positive results and thus reduces the 
specificity of the test [35-38]. Partly this problem is solved in the competitive ELISA (cELISA), where the specific epitopes of Brucella O-polysaccharides are used as antigens, but the sensitivity of cELISA is significantly lower than the iELISA $[39,40]$.

Another interesting method is the fluorescence polarization assay (FPA) [34]. It is based on the physical principle of the mass-dependent change of the molecules rotation speed in a liquid medium. The smaller the molecule, the faster it rotates and the depolarization of a polarized beam of light occurs. In FPA the serum sample is incubated with a specific Brucella antigen, conjugated with a fluorescent label. In case there are anti-Brucella antibodies in the serum, large fluorescently labeled antigen-antibody complex is formed, which can easily be distinguished from the unbound antigen negative control. FPA method has a high specificity but less sensitivity than iELISA [41]. In Europe and the USA FPA method is used in programs to monitor and control the spread of brucellosis, but it requires special equipment and it is not suitable for rapid and easy testing.

The Brucella specific seropositive response is the confirmation of the infection, but it doesn't provide any information about the type of Brucella species, the time of infection, the phase of the disease, or even that the animal actually has the disease at the time of sample collection, since antibody titer can be quite high for a long time after the acute phase of the disease. It is known that in the acute phase of brucellosis the IgM antibodies are primary produced, and then, after a short period of time, IgG antibodies are produced [2]. Amount of IgG antibodies may be reduced after treatment, however, a high level of IgG antibodies circulating in the blood, can persist in the absence of the acute phase of the disease. At the chronic form of brucellosis IgG antibodies dominate in blood samples, while IgM antibodies are not detected or found only in small amounts. Most iELISA methods predominantly detect IgG and its subclasses, and Wright reaction mainly detects IgM [1]. Thus, using the combination of these methods it is possible to obtain the kinetics of the immune response and to distinguish between acute and chronic phases of the disease.

Another group of tests are allergic or skin-allergic tests for brucellosis [2]. It identifies specific cellular immune response to the under the skin administration of Brucella antigen. This test clearly confirms the actual cases of brucellosis and allows distinguishing them from the false-positive results of other tests.

\section{Recent Advances in Proteomic Methods of Brucella Diagnostics}

Both classical microbiological and serological methods of brucellosis diagnosis, as well as PCR based methods have some significant disadvantages despite their inten- sive development. For serological methods the main disadvantage is the lack of specificity. As it was already mentioned, Brucella smooth LPS are very immunogenic, but they have a cross-reactivity with LPS of other genera of bacteria. This fact significantly reduces the specificity of the diagnostics. Moreover, some species of Brucella (e.g. from B. canis and B. ovis) have rough surface LPSs and cannot be detected using standard tests for the presence of antibodies against smooth LPSs. So the problems of recognition of stages and forms of brucellosis, as well as the disjunction of brucellosis infection and vaccination events in cattle are still remain unsolved.

An alternative immunological method of brucellosis diagnostics, which is able to solve the above mentioned problems, is the detection of antibodies to Brucella species-specific proteins in serum or in other animal tissues and body fluids. Over the last twenty years there have been many efforts to identify the immunologically active Brucella proteins to which antibodies are produces in the organism of an infected animal or individual in a quantity sufficient for their detection. For example, 31-kDa Brucella cell-surface protein (BCSP31) was isolated, cloned and characterized from the Brucella abortus cell extract $[42,43]$. It is an immunogenic surface protein, which is highly conserved (100\% homology) among $B$. melitensis, B. abortus and B. Suis. Moreover, the recombinant BCSP31 is efficiently expressed and purified from E.coli cells, as well as specific monoclonal antibodies against BCSP31 have been obtained [44]. The combination of these properties makes BCSP31 a potential candidate for use in brucellosis diagnostic tests.

Besides BCSP31, $26 \mathrm{kDa}$ periplasmic protein (bp 26), isolated from B. abortus [45] and B. melitensis [46,47], has also been cloned and characterized as an immunodominant antigen. This protein was detected in human and sheep blood in the acute phase of the disease, but not for chronic or asymptomatic form of the disease. Therefore bp26 can be used as a marker of acute brucellosis. Another $60 \mathrm{kDa}$ protein $\mathrm{HtrA} / \mathrm{DegP}$, which demonstrated high activity in the reaction with serum from brucellosis infected animals, was isolated from a collection of Brucella recombinant proteins, cloned and expressed in E.coli. HtrA/DegP specific antibodies were detected in the serum of animals experimentally infected with $B$. abortus, B. melitensis and B. canis [48]. High immunogenicity was also observed for Brucella proteins Omp16, Omp10, chaperone GroEL, VirB operon surface proteins, the chaperone protein trigger factor TF [48-54]. In spite of the intensive search for Brucella proteins suitable for vaccination and diagnostic purposes over the years, the protein, which suits all the requirements and is able to replace LPS as a diagnostic antigen, is still to be found [55].

Recently the results of Brucella study using system 
biology methods of genomics and proteomics were published. Through the sequencing of the complete genomes of 8 bacterial isolates from five Brucella species (Brucella abortus, Brucella melitensis, Brucella suis, Brucella ovis and Brucella canis) [56], it became possible to create a library of the predicted protein-coding open reading frames (ORFs) in Brucella genome. Such a ORFeome library was made for B. melitensis [57], but since the high degree of homology between the genomes of Brucella species [56], B. melitensis ORFeome library can be used to analyze any type of Brucella. The protein coding DNA fragments were amplified using PCR and cloned into the DNA vector, which has been transformed into E. coli cells. The resulting library consisted of 3091 clones, each containing a single ORF. It was 96.7 percent of the total number of found ORF [57]. B. melitensis ORFeome library was immobilized on DNA microarray and used for the analysis of the expression of Brucellaabortus genes [58].

System biology methods also provide possibility to identify the antibodies produced by the organism in response to Brucella infection and also to predict the serodiagnostic properties of bacterial antigens. Li Liang with coauthors analyzed antibodies produced by the organism of human and goats in response to the acute form of brucellosis caused by $B$. melitensis using proteomics methods [55,59]. The protein microarray, containing 1406 B. melitensis proteins, was designed. It was used for the analysis of human serum samples from the patients with acute brucellosis among the population of Peru, where brucellosis is endemic. As a negative control serum samples of clinically healthy patients from Peru and USA, where brucellosis cases are rare, were used. The immune response to brucellosis in goats, experimentally infected with B. melitensis, was also studied. 13 Brucella proteins (serodiagnostic antigens) were identified, for which antibodies were detected in the serum of Brucella infected patients, but not patients from the control group. 18 serodiagnostic antigens, recognized by the immune system, in experimentally infected goats, but not healthy animals, were also detected. Antibodies only against two common serodiagnostic antigens were detected in serum of both humans and goats. The observed results made the authors think that the immune response of experimentally infected animals (natural hosts of Brucella), differs from that one in humans [55].

In another work, using a protein microarray containing complete proteome of B. melitensis (3046 proteins), authors identified 122 immunodominant and 33 serodiagnostic antigens and characterized them according to their possible function, structure and cellular localization, significant for immunogenicity [59]. This microarray was used to diagnose a patient with a focal form of skeletal muscle brucellosis with negative results in agglutination test. Moreover, for the first time the kinetics of antibody production in humans not only in the acute phase of the disease, but also in the chronic form was measured using this microarray. It was shown that immunopathogenicity mechanisms of acute and chronic brucellosis have fundamental differences [60].

\section{Conclusions}

Diagnosis of brucellosis in livestock and humans is not a simple task. The "gold standard" of Brucella detection is its recovery from the host, but it is a labor-intensive and time-consuming procedure, that has to be done in specially equipped laboratories. Since that molecular diagnostic tools are becoming more and more common for brucellosis diagnostics. They are rapid, safe and cost effective in comparison with direct bacteriological testing.

PCR-based methods for Brucella identification in biological samples are becoming very important tools for brucellosis diagnostics at the species level and biovar level. However, PCR analysis of the clinical samples must be fully validated before the routine use in laboratory testing for brucellosis. Multiplex real-time PCR seems to be the most promising method of Brucella DNA detection. The next-generation sequencing methods can also be used for diagnostics of brucellosis. They are still too expensive, but they are becoming more and more popular and accessible.

Serological tests for brucellosis have been invented more than a century ago, however the perfect test has still not been developed. Traditional serological methods of Brucella diagnostics are based on the detection of antibodies, specific to the surface LPS. It leads to a low specificity of these tests. An alternative approach, which is able to solve the above mentioned problem, is the detection of antibodies to Brucella species-specific proteins. It seems like that there is no single universal immunodominant protein, but up-to-date proteomic methods allow analysis of the whole Brucella proteome in order to identify a series of such proteins. The methods of system biology can not only be successfully used in the diagnosis of brucellosis, but they can expand the understanding of fundamental biological processes in the Brucella infected organism, including those leading to the great variety in the immune response [61].

The technological advances should be associated with the development of new immunoassay multiplex technologies with fluorescent or chemiluminescent detection systems, i.e. protein microarrays. Recently, the mass spectrometry approach was suggested for identification and genotyping of Brucella [62]. This method provides fast and reliable identification of bacteria at the species level, but it requires special complex equipment, which is available only in big laboratories. 
All the above mentioned methods can be extremely sensitive and accurate, but they can't be used in field conditions, for example in farms, where laboratory testing is not available. Since that they are more suitable for Brucella detection in humans, but not in livestock. For the routing screening of animals simple and accurate point-of-care tests (such as lateral flow assays, immunochromatographic strips, portable microfluidic devices, cathodic electrochemiluminescence chips) are needed. So in our opinion the development of brucellosis diagnostic test is associated with easy-to-use point-of-care test for the preliminary diagnostics and high sensitive and specific methods for the further laboratory testing.

\section{REFERENCES}

[1] J. Godfroid, K. Nielsen and C. Saegerman, "Diagnosis of Brucellosis in Livestock and Wildlife," Croatian Medical Journal, Vol. 51, No. 4, 2010, pp. 296-305. doi:10.3325/cmj.2010.51.296

[2] P. P. Poester, K. Nielsen, L. E. Samartino and W. L. Yu, "Diagnosis of Brucellosis," The Open Veterinary Science Journal, Vol. 4, 2010, pp. 46-60.

[3] M. J. Corbel, "Brucellosis: An Overview," Proceedings of the 1st International Conference on Emerging Zoonoses: Emerging Infectious Diseases, Jerusalem, AprilJune 1997, pp. 213-221.

[4] World Health Organization, "Fact Sheet N173," World Health Organization, Geneva, 1997.

[5] G. Pappas, P. Papadimitriou, N. Akritidis, L. Christou and E. V. Tsianos, "The New Global Map of Human Brucellosis," Lancet Infectious Diseases, Vol. 6, No. 2, 2006, pp. 91-99. doi:10.1016/S1473-3099(06)70382-6

[6] Office International des Épizooties, "Manual of Standards for Diagnostic Tests and Vaccines," Office International des Épizooties, Paris, 2000.

[7] CDC, "Public Health Consequences of a False-Positive Laboratory Test Result for Brucella-Florida, Georgia, and Michigan, 2005," Morbidity and Mortality Weekly Report (MMWR), Vol. 57, No. 22, 2008, pp. 603-605.

[8] P. Yagupsky, "Detection of Brucellae in Blood Cultures," Journal of Clinical Microbiology, Vol. 37, No. 11, 1999, pp. 3437-3442.

[9] S. R. Porter, G. Czaplicki, J. Mainil, R. Guattéo, C. Saegerman and Q. Fever, "Current State of Knowledge and Perspectives of Research of a Neglected Zoonosis," International Journal of Microbiology, Vol. 2011, 2011, Article ID: 248418. doi:10.1155/2011/248418

[10] G. Pappas, N. Akritidis, M. Bosilkovski and E. Tsianos, "Brucellosis," The New England Journal of Medicine, Vol. 352, No. 22, 2005, pp. 2325-2336. doi:10.1056/NEJMra050570

[11] J.-M. Verger, F. Grimont, P. A. D. Grimont and M. Grayon, "Brucella, a Monospecific Genus as Shown by Deoxyribonucleic Acid Hybridization," International Journal of Systematic Bacteriology, Vol. 35, No. 3, 1985, pp. 292-295. doi:10.1099/00207713-35-3-292
[12] W. L. Yu and K. Nielsen, "Review of Detection of Brucella spp. by Polymerase Chain Reaction," Croatian Medical Journal, Vol. 51, No. 4, 2010, pp. 306-313. doi:10.3325/cmj.2010.51.306

[13] M. M. Baddour and D. H. Alkhalifa, "Evaluation of Three Polymerase CHAIN Reaction Techniques for Detection of Brucella DNA in Peripheral Human Blood," Canadian Journal of Microbiology, Vol. 54, No. 5, 2008, pp. 352357. doi:10.1139/W08-017

[14] L. A. Dauphin, R. J. Hutchins, L. A. Bost and M. D. Bowen, "Evaluation of Automated and Manual Commercial DNA Extraction Methods for Recovery of Brucella DNA from Suspensions and Spiked Swabs," Journal of Clinical Microbiology, Vol. 47, No. 12, 2009, pp. 3920-3926. doi:10.1128/JCM.01288-09

[15] S. Ouahrani-Bettach, M. P. Soubrier and J. P. Liautard, "IS6501-Anchored PCR for the Detection and Identification of Brucella Species and Strains," Journal of Applied Bacteriology, Vol. 81, No. 2, 1996, pp. 154-160. doi:10.1111/j.1365-2672.1996.tb04493.x

[16] K. Imaoka, M. Kimura, M. Suzuki, T. Kamiyama and A. Yamada, "Simultaneous Detection of the Genus Brucella by Combinatorial PCR," Japanese Journal of Infectious Diseases, Vol. 60, No. 2-3, 2007, pp. 137-139.

[17] V. Hinic, I. Broadard, A. Thomann, Z. Cvetnic, P. V. Mkaya, J. Frey and C. Abril, "Novel Identification and Differentiation of Brucella melitensis, B. abortus, B. suis, B. ovis, B. canis, and B. neotmae Suitable for Both Conventional and Real-Time PCR Systems," Journal of Microbiological Methods, Vol. 75, No. 2, 2008, pp. 375-378. doi:10.1016/j.mimet.2008.07.002

[18] D. S. Leal-Klevezas, I. O. Martinez-Vazquez, J. GarciaCantu, A. Lopez-Merina and J. P. Martinez-Soriano, "Use of Polymerase Chain Reaction to Detect Brucellaabortus Biovar 1 in Infected Goats," Veterinary Microbiology, Vol. 75, No. 1, 2000, pp. 91-97. doi:10.1016/S0378-1135(00)00200-5

[19] F. J. Sangari and J. Aguero, "Identification of Brucella abortus B19 Vaccine Strain by the Detection of DNA Polymorphism at the ery Locus," Vaccine, Vol. 12, No. 5, 1994, pp. 435-438. doi:10.1016/0264-410X(94)90121-X

[20] R. Vemulapalli, J. R. McQuiston, G. G. Shurig, N. Srirangnathan, S. M. Halling and S. M. Boyle, "Identification of an IS711 Element Interrupting the wboA Gene of Brucella abortus Vaccine Strain RB51 and a PCR Assay to Distinguish Strain RB51 from Other Brucella Species and Strains," Clinical and Diagnostic Laboratory Immunology, Vol. 6, No. 5, 1999, pp. 760-764.

[21] B. J. Bricker and S. M. Halling, "Differentiation of Brucella abortus bv. 1, 2 and 4, Brucella melitensis, Brucella ovis, and Brucella suis bv. 1 by PCR," Journal of Clinical Microbiology, Vol. 32, No. 11, 1994, pp. 2660-2666.

[22] D. R. Ewalt, "Screening Method for Differentiation of Brucella abortus Field Strain Isolates and Vaccine Strains, 19 and RB51," Journal of Clinical Microbiology, Vol. 38, No. 8, 2000, pp. 3085-3086.

[23] A. A. Ocampo-Sosa, J. Agüero-Balbin and J. M. GarciaLobo, "Development of a New PCR Assay to Identify 
Brucella abortus Biovars 5, 6 and 9 and New Subgroup 3 b of Biovar 3," Veterinary Microbiology, Vol. 110, No. 1-2, 2005, pp. 41-51.

[24] W. L. Yu and K. Nielsen, "Review of Detection of Brucella spp. by Polymerase Chain Reaction," Croatian Medical Journal, Vol. 51, No. 4, 2010, pp. 306-313. doi:10.3325/cmj.2010.51.306

[25] B. B. Alarcón, B. Vicedo and R. Aznar, "PCR-Based Procedures for Detection of Staphylococcus aureus and Their Application in Food," Journal of Applied Microbiology, Vol. 100, No. 2, 2006, pp. 352-364. doi:10.1111/j.1365-2672.2005.02768.x

[26] M. M. Kattar, P. A. Zallouab, G. F. Araja, J. SamahaKfourya, H. Shbakloe, S. S. Kanjb, S. Khalifea and M. Deebc, "Development and Evaluation of Real-Time Polymerase Chain Reaction Assays on Whole Blood and Paraffin-Embedded Tissues for Rapid Diagnosis of $\mathrm{Hu}-$ man Brucellosis," Diagnostic Microbiology and Infectious Disease, Vol. 59, No. 1, 2007, pp. 23-32. doi:10.1016/j.diagmicrobio.2007.04.002

[27] B. J. Bricker, D. R. Ewalt and S. M. Halling, "Brucella 'HOOF-Prints': Strain Typing by Multi-Locus Analysis of Variable Number Tandem Repeats (VNTRs)," BMC Microbiology, Vol. 3, 2003, p. 15. doi:10.1186/1471-2180-3-15

[28] F. Le Fleche, I. Jacques, M. Grayon, S. Al Dahouk, P. Bouchon, F. Denoeud, K. Nöckler, H. Neubauer, L. A. Guilloteau and G. Vergnaud, "Evaluation and Selection of Tandem Repeat Loci for a Brucella MLVA Typing Assay," BMC Microbiology, Vol. 6, 2006, p. 9. doi:10.1186/1471-2180-6-9

[29] G. G. Alton, L. M. Jones, R. D. Angus and J. M. Verger, "Techniques for the Brucellosis Laboratory," Institute National de la Recherche Agronomique, Paris, 1988.

[30] K. H. Nielsen, "Diagnosis of Brucellosis by Serology," Veterinary Microbiology, Vol. 90, No. 1-4, 2002, pp. 447-459.

[31] W. Hill, "Standardization of the Complement Fixation test for Brucellosis," Bull OIE, Vol. 60, 1963, pp. 401410.

[32] I. Dohoo, P. Wright, G. Ruckerbauer, B. Samagh, F. Robertson and L. Forbes, "A Comparison of Five Serological Tests for Bovine Brucellosis," The Canadian Journal of Veterinary Research, Vol. 50, No. 4, 1986, pp. 485-493.

[33] X. Rojas and O. Alonso, "ELISA for the Diagnosis and Epidemiology of Brucella abortus Infection in Cattle in Chile," IAEA TECDOC, Vienna, 1994, pp. 77-82.

[34] L. Samartino, R. Gregoret, D. Gall and K. Nielsen, "Fluorescence Polarization Assay: Application to the Diagnosis of Bovine Brucellosis in Argentina," Journal of Immunoassay, Vol. 20, No. 3, 1999, pp. 115-120. doi:10.1080/01971529909349347

[35] P. Pardon, R. Sanchis, G. Molenat, J. Marly and D. Renard, "Serological and Allergic Reactions of Ewes after Simultaneous Vaccinations with Two Living Attenuated Strains of Brucella and Salmonella," Annales de Recherches Veterinaires, Vol. 21, No. 2, 1990, pp. 153-160.
[36] P. M. Muñoz, C. M. Marín, D. Monreal, D. González, B. Garin-Bastuji, R. Díaz, R. C. Mainar-Jaime, I. Moriyón and J. M. Blasco, "Efficacy of Several Serological Tests and Antigens for Diagnosis of Bovine Brucellosis in the Presence of False-Positive Serological Results Due to Yersinia enterocolitica O:9," Clinical and Vaccine Immunology, Vol. 12, No. 1, 2005, pp. 141-151. doi:10.1128/CDLI.12.1.141-151.2005

[37] V. Weynants, A. Tibor, P. A. Denoel, C. Saegerman, J. Godfroid, P. Thiange and J. J. Letesson, "Infection of Cattle with Yersinia enterocolitica O:9 a Cause of the False Positive Serological Reactions in Bovine Brucellosis Diagnostic Tests," Veterinary Microbiology, Vol. 48, No. 1-2, 1996, pp. 101-112. doi:10.1016/0378-1135(95)00153-0

[38] K. Nielsen, P. Smith, J. Widdison, D. Gall, L. Kelly, W. Kelly and P. Nicoletti, "Serological Relationship between Cattle Exposed to Brucella abortus, Yersinia enterocolitica O:9 and Escherichia coli O157:H7," Veterinary Microbiology, Vol. 100, No. 1-2, 2004, pp. 25-30. doi:10.1016/j.vetmic.2003.12.010

[39] K. H. Nielsen, L. Kelly, D. Gall, P. Nicoletti and W. Kelly, "Improved Competitive Enzyme Immunoassay for the Diagnosis of Bovine Brucelliosis," Veterinary Immunology and Immunopathology, Vol. 46, No. 3-4, 1995, pp. 285-291. doi:10.1016/0165-2427(94)05361-U

[40] V. Weynants, D. Gilson, A. Cloeckaert, P. A. Denoel, A. Tibor, P. Thiange, J. N. Limet and J. J. Letesson, "Characterization of a Monoclonal Antibody Specific for Brucella Smooth Lipopolysaccharide and Development of a Competitive Enzyme-Linked Immunosorbent Assay to Improve the Serological Diagnosis of Brucellosis," Clinical and Diagnostic Laboratory Immunology, Vol. 3, No. 3, 1996, pp. 309-314.

[41] J. A. McGiven, J. D. Tucker, L. L. Perrett, J. A. Stack, S. D. Brew and A. P. MacMillan, "Validation of FPA and cELISA for the Detection of Antibodies to Brucella abortus in Cattle Sera and Comparison to SAT, CFT, and iELISA," Journal of Immunological Methods, Vol. 278, No. 1-2, 2003, pp. 171-178.

doi:10.1016/S0022-1759(03)00201-1

[42] J. E. Mayfield, B. J. Bricker, H. Godfrey, R. M. Crosby, D. J. Knight, S. M. Halling, D. Balinsky and L. B. Tabatabai, "The Cloning, Expression, and Nucleotide Sequence of a Gene Coding for an Immunogenic Brucella abortus Protein," Gene, Vol. 63, No. 1, 1988, pp. 1-9. doi:10.1016/0378-1119(88)90540-9

[43] B. J. Bricker, L. B. Tabatabai, B. L. Deyoe and J. E. Mayfield, "Conservation of Antigenicity in a 31-kDa Brucella Protein," Veterinary Microbiology, Vol. 18, No. 3-4, 1988, pp. 313-325. doi:10.1016/0378-1135(88)90096-X

[44] L. Zhang, X. A. Wu, F. L. Zhang, C. H. An, Y. X. Sun, W. T. Bai and Z. K. Xu, "Soluble Expression and Purification of Brucella Cell Surface Protein (BCSP31) of Brucella melitensis and Preparation of Anti-BCSP31 Monoclonal Antibodies," Molecular Biology Reports, Vol. 39, No. 1, 2012, pp. 431-438. doi:10.1007/s11033-011-0755-9

[45] O. L. Rossetti, A. I. Arese, M. L. Boschiroli and S. L. 
Cravero, "Cloning of Brucella abortus Gene and Characterization of Expressed 26-Kilodalton Periplasmic Protein: Potential Use for Diagnosis," Journal of Clinical Microbiology, Vol. 34, No. 1, 1996, pp. 165-169.

[46] A. Cloeckaert, H. Salih-AljDebbarh, N. Vizcaino, E. Saman, G. Dubray and M. S. Zygmunt, "Cloning, Nucleotide Sequence, and Expression of the Brucella melitensis bp26 Gene Coding for a Protein Immunogenic in Infected Sheep," FEMS Microbiology Letters, Vol. 140, No. 2-3, 1996, pp. 139-144. doi:10.1111/j.1574-6968.1996.tb08327.x

[47] L. E. Lindler, T. L. Hadfield, B. D. Tall, N. J. Snellings, F. A. Rubin, L. L. Van de Verg, D. Hoover and R. L. Warren, "Cloning of a Brucella melitensis Group 3 Antigen Gene Encoding Omp28, a Protein Recognized by the Humoral Immune Response during Human Brucellosis," Infection and Immunity, Vol. 64, No. 7, 1996, pp. 24902499.

[48] R. M. Roop 2nd, T. W. Fletcher, N. M. Sriranganathan, S. M. Boyle and G. G. Schurig, "Identification of an Immunoreactive Brucella abortus HtrA Stress Response Protein Homolog," Infection and Immunity, Vol. 62, No. 3, 1994, pp. 1000-1007.

[49] A. Tibor, V. Weynants, P. Denoel, B. Lichtfouse, X. De Bolle, E. Saman, J. N. Limet and J. J. Letesson, "Molecular Cloning, Nucleotide Sequence, and Occurrence of a 16.5-Kilodalton Outer Membrane Protein of Brucella abortus with Similarity to Pal Lipoproteins," Infection and Immunity, Vol. 62, No. 9, 1994, pp. 3633-3639.

[50] J. P. Connolly, D. Comerci, T. G. Alefantis, A. Walz, M. Quan, R. Chafin, P. Grewal, C. V. Mujer, R. A. Ugalde and V. G. DelVecchio, "Proteomic Analysis of Brucella abortus Cell Envelope and Identification of Immunogenic Candidate Proteins for Vaccine Development," Proteomics, Vol. 6, No. 13, 2006, pp. 3767-3780. doi:10.1002/pmic. 200500730

[51] W. Tan, X. R. Wang, Y. Nie, C. Wang, L. Q. Cheng, X. C. Wang, R. Zhang and G. M. Yan, "Recombinant VirB5 Protein as a Potential Serological Marker for the Diagnosis of Bovine Brucellosis," Molecular and Cellular Probes, Vol. 26, No. 3, 2012, pp. 127-131. doi:10.1016/j.mcp.2012.02.003

[52] H. G. Rolarn, A. B. den Hartigh, M. Kahl-McDonagh, T. Ficht, L. G. Adams and R. M. Tsolis, "VirB12 Is a Serological Marker of Brucella Infection in Experimental and Natural Hosts," Clinical and Vaccine Immunology, Vol. 15, No. 2, 2008, pp. 208-214. doi:10.1128/CVI.00374-07

[53] A. P. Cannella, R. M. Tsolis, L. Liang, P. L. Felgner, M. Saito, A. Sette, E. Gotuzzo and J. M. Vinetz, "AntigenSpecific Acquired Immunity in Human Brucellosis: Implications for Diagnosis, Prognosis, and Vaccine Development," Frontiers in Cellular and Infection Microbiology, Vol. 2, 2012, p. 1. doi:10.3389/fcimb.2012.00001

[54] X. Yang, M. Hudson, N. Walters, R. F. Bargatze and D. W. Pascual, "Selection of Protective Epitopes for Brucella melitensis by DNA Vaccination," Infection and Immunity, Vol. 73, No. 11, 2005, pp. 7297-7303.
doi:10.1128/IAI.73.11.7297-7303.2005

[55] L. Liang, D. Leng, C. Burk, R. Nakajima-Sasaki, M. A. Kayala, V. L. Atluri, J. Pablo, B. Unal, T. A. Ficht, E. Gotuzzo, M. Saito, W. J. Morrow, X. Liang, P. Baldi, R. H. Gilman, J. M. Vinetz, R. M. Tsolis and P. L. Felgner, "Large Scale Immune Profiling of Infected Humans and Goats Reveals Differential Recognition of Brucella melitensis Antigens," PLOS Neglected Tropical Diseases, Vol. 4, No. 5, 2010, p. e673. doi:10.1371/journal.pntd.0000673

[56] P. S. Chain, D. J. Comerci, M. E. Tolmasky, F. W. Larimer, S. A. Malfatti, L. M. Vergez, F. Aguero, M. L. Land, R. A. Ugalde and E. Garcia, "Whole-Genome Analyses of Speciation Events in Pathogenic Brucellae," Infection and Immunity, Vol. 73, No. 12, 2005, pp. 8353-8361. doi:10.1128/IAI.73.12.8353-8361.2005

[57] A. Dricot, J. F. Rual, P. Lamesch, N. Bertin, D. Dupuy, T. Hao, C. Lambert, R. Hallez, J. M. Delroisse, J. Vandenhaute, I. Lopez-Goñi, I. Moriyon, J. M. Garcia-Lobo, F. J. Sangari, A. P. Macmillan, S. J. Cutler, A. M. Whatmore, S. Bozak, R. Sequerra, L. Doucette-Stamm, M. Vidal, D. E. Hill, J. J. Letesson and X. De Bolle, "Generation of the Brucella melitensis ORFeome Version 1.1," Genome Research, Vol. 14, No. 10B, 2004, pp. 2201-2206. doi:10.1101/gr.2456204

[58] C. Viadas, M. C. Rodriguez, J. M. Garcia-Lobo, F. J. Sangari and I. Lopez-Goni, "Construction and Evaluation of an ORFeome-Based Brucella Whole-Genome DNA Microarray," Microbial Pathogenesis, Vol. 47, No. 4, 2009, pp. 189-195. doi:10.1016/j.micpath.2009.06.002

[59] L. Liang, X. Tan, S. Juarez, H. Villaverde, J. Pablo, R. Nakajima-Sasaki, E. Gotuzzo, M. Saito, G. Hermanson, D. Molina, S. Felgner, W. J. Morrow, X. Liang, R. H. Gilman, D. H. Davies, R. M. Tsolis, J. M. Vinetz and P. L. Felgner, "Systems Biology Approach Predicts Antibody Signature Associated with Brucella melitensis Infection in Humans," Journal of Proteome Research, Vol. 10, No. 10, 2011, pp. 4813-4824. doi:10.1021/pr200619r

[60] A. P. Cannella, J. C. Lin, L. Liang, V. Atluri, E. Gotuzzo, P. L. Felgner, R. M. Tsolis and J. M. Vinetz, "Serial Kinetics of the Antibody Response against the Complete Brucella melitensis ORFeome in Focal Vertebral Brucellosis," Journal of Clinical Microbiology, Vol. 50, No. 3, 2012, pp. 922-926. doi:10.1128/JCM.05298-11

[61] Y. He, "Analyses of Brucella Pathogenesis, Host Immunity, and Vaccine Targets Using Systems Biology and Bioinformatics," Frontiers in Cellular and Infection Microbiology, Vol. 2, 2012, p. 2. doi:10.3389/fcimb.2012.00002

[62] L. Ferreira, S. V. Castano, F. Sanchez-Juanes, S. Gonzalez-Cabrero, F. Menegotto, A. Orduna-Domingo, J. M. Gonzales-Buitrago and J. L. Munoz-Bellido, "Identification of Brucella by MALDI-TOF Mass Spectrometry. Fast and Reliable Identification from Agar Plates and Blood Cultures," PLoS One, Vol. 5, No. 12, 2010, pp. 1-8. doi:10.1371/journal.pone.0014235 